[3] Rodero, M.P.; Decalf, J.; Bondet, V.; Hunt, D.; Rice, G.I.;Werneke, S.; McGlasson, S.L.; Alyanakian, M.A.; Bader-Meunier, B.; Barnerias, C., et al. Detection of interferon alpha protein reveals differential levels and cellular sources in disease. J. Exp. Med. 2017, 214, 1547-1555. DOI: 10.1084/jem.20161451.

[4] Mathian, A.; Mouries-Martin, S.; Dorgham, K.; Devilliers, H.; Yssel, H.; Garrido Castillo, L.; Cohen-Aubart, F.; Haroche, J.; Hie, M.; Pineton de Chambrun, M., et al. Ultrasensitive serum interferon-alpha quantification during SLE remission identifies patients at risk for relapse. Ann. Rheum. Dis. 2019, 78, 1669-1676. DOI: 10.1136/annrheumdis-2019-215571.

Disclosure of Interests: None declared

DOI: 10.1136/annrheumdis-2021-eular.2056

\section{POS0190 ASSOCIATION BETWEEN OSTEOARTHRITIS-RELATED SERUM BIOCHEMICAL MARKERS OVER 11 YEARS AND KNEE SYMPTOMS IN MIDDLE-AGED ADULTS}

A. Singh ${ }^{1}$, L. Blizzard ${ }^{2}$, A. Venn ${ }^{1}$, G. Jones ${ }^{1}$, J. Burgess ${ }^{1,3}$, V. Parameswaran ${ }^{1,3}$, C. Ding ${ }^{1,4,5}$, B. Antony ${ }^{1} .{ }^{1}$ Menzies Institute for Medical Research, Musculoskeletal Health and Disease, Hobart, Australia; ${ }^{2}$ Menzies Institute for Medical Research, Statistics, Hobart, Australia; ${ }^{3}$ Royal Hobart Hospital, Department of Endocrinology, Hobart, Australia; ${ }^{4}$ Monash University, Department of Epidemiology and Preventive Medicine, Clayton, Australia; ${ }^{5}$ Southern Medical University, Clinical Research Centre, Zhujiang Hospital, Guangzhou Shi, China

Background: Serum levels of cartilage and joint-specific biochemical markers such as cartilage oligomeric matrix protein (COMP), matrix metalloproteinase (MMP)-3, and hyaluronan (HA) are associated with cartilage degradation, joint tissue degradation, and synovitis in patients with OA. Change in these biomarkers may precede the morphological and clinical manifestations of OA and therefore have been explored as predictive markers in OA. However, few studies have evaluated the association of OA-related biomarkers with knee symptoms in general population-based middle-aged adults

Objectives: To describe the associations between OA-related biomarkers and knee symptoms in middle-aged adults followed up over $10-13$ years

Methods: Blood samples were collected during the Childhood Determinants of Adult Health (CDAH)-1 study at baseline (year: 2004-06, age: 26-36 years) and 10-13 year follow-up (CDAH-3; year: 2014-2019, age: 36-49 years). Serum samples from baseline $(n=156)$ and follow-up $(n=167)$ were analyzed for three OA-related biomarkers - namely COMP, MMP-3, and HA- using ELISA. Knee symptoms (pain, stiffness, and dysfunction) were assessed using the WOMAC scale during the $\mathrm{CDAH}-3$ phase. Univariable and multivariable (adjusted for age

Table 1. Cross-sectional and longitudinal association between WOMAC symptoms and OA-related biomarkers

\begin{tabular}{|c|c|c|}
\hline \multirow[t]{2}{*}{ Variables } & $\begin{array}{l}\text { Longitudinal } \\
\text { Biomarker at } C D A H-1, \text { knee symptom } \\
\text { at } C D A H-3\end{array}$ & $\begin{array}{l}\text { Cross-sectional } \\
\text { Biomarker at } C D A H-3, \text { knee } \\
\text { symptom at } C D A H-3\end{array}$ \\
\hline & $\begin{array}{l}\text { Adjusted }{ }^{\dagger} \text { Coef. }(95 \% \mathrm{Cl}) \\
\text { p-value }\end{array}$ & $\begin{array}{l}\text { Adjusted } d^{\ddagger} \text { Coef. }(95 \% \mathrm{Cl}) \\
\text { p-value }\end{array}$ \\
\hline \multicolumn{3}{|c|}{ COMP (Predictor) } \\
\hline WOMAC-total & $\begin{array}{l}1.047(1.035,1.060) \\
p<0.01\end{array}$ & $\begin{array}{l}1.088(1.017,1.159) \\
p=0.01\end{array}$ \\
\hline Pain & $\begin{array}{l}1.026(1.002,1.050) \\
p=0.03\end{array}$ & $\begin{array}{l}1.156(0.989,1.324) \\
p=0.04\end{array}$ \\
\hline Stiffness & $\begin{array}{l}1.019(0.988,1.051) \\
p=0.23\end{array}$ & $\begin{array}{l}0.877(0.708,1.057) \\
p=0.12\end{array}$ \\
\hline Dysfunction & $\begin{array}{l}1.045(1.030,1.061) \\
p<0.01\end{array}$ & $\begin{array}{l}1.040(0.949,1.130) \\
p=0.38\end{array}$ \\
\hline \multicolumn{3}{|c|}{ MMP3 (Predictor) } \\
\hline WOMAC-total & $\begin{array}{l}1.026(1.020,1.031) \\
p<0.01\end{array}$ & $\begin{array}{l}1.017(1.010,1.023) \\
p<0.01\end{array}$ \\
\hline Pain & $\begin{array}{l}1.020(1.009,1.030) \\
p<0.01\end{array}$ & $\begin{array}{l}1.013(1.001,1.025) \\
p=0.03\end{array}$ \\
\hline Stiffness & $\begin{array}{l}1.020(1.004,1.035) \\
p=0.01\end{array}$ & $\begin{array}{l}1.004(.987,1.021) \\
p=0.66\end{array}$ \\
\hline $\begin{array}{l}\text { Dysfunction } \\
\text { HA (Predictor) }\end{array}$ & $\begin{array}{l}1.029(1.022,1.037) \\
p<0.01\end{array}$ & $\begin{array}{l}1.019(1.010,1.026) \\
p<0.01\end{array}$ \\
\hline WOMAC-total & $\begin{array}{l}0.995(0.991,0.999) \\
\mathrm{p}=0.01\end{array}$ & $\begin{array}{l}1.007(1.003,1.010) \\
p<0.01\end{array}$ \\
\hline Pain & $\begin{array}{l}0.999(0.991,1.006) \\
p=0.75\end{array}$ & $\begin{array}{l}1.008(1.002,1.015) \\
p=0.01\end{array}$ \\
\hline Stiffness & $\begin{array}{l}0.989(0.980,0.998) \\
\mathrm{p}=0.03\end{array}$ & $\begin{array}{l}0.997(0.989,1.007) \\
p=0.65\end{array}$ \\
\hline Dysfunction & $\begin{array}{l}1.003(0.998,1.009) \\
p=0.22\end{array}$ & $\begin{array}{l}1.015(1.010,1.020) \\
p<0.01\end{array}$ \\
\hline
\end{tabular}

Bold denotes statistically significant'Model adjusted for age, sex, and BMI sex, and body mass index (BMI)) zero-inflated Poisson regression models with random effects were used to describe the above associations

Results: The prevalence of knee pain was $46 \%$. In the multivariable model, adjusted for age, sex, and $\mathrm{BMI}$, there was a significant positive association between COMP $(\beta=1.156,95 \% \mathrm{Cl}: 0.989,1.324 ; p=0.04)$, MMP-3 $(\beta=1.013,95 \% \mathrm{Cl}$ 1.001,1.025; $\mathrm{p}=0.02)$, and $\mathrm{HA}({ }=1.008,95 \% \mathrm{Cl}: 1.002,1.015, \mathrm{p}=0.01)$ with knee pain and WOMAC-total score (Table 1) in middle-aged adults. The increase in knee pain per $\mathrm{ng} / \mathrm{ml}$ increase in COMP, MMP-3, and HA was $15.7 \%, 1.3 \%$, and $0.8 \%$, respectively. The overall mean biomarker levels decreased over 10-13 years; however, the mean WOMAC-total scores were higher in participants whose COMP and HA levels increased (COMP: 24 (27.31), HA: 14.20 (22.60)) compared to those in whom it decreased or remained stable (COMP 9.84 (16.83), and HA: 8.28 (13.22)) during this period. There was a significant positive association between COMP $(\beta=1.026,95 \% \mathrm{Cl}: 1.002,1.050, p=0.03)$ and MMP-3 ( $s=1.020,95 \% \mathrm{Cl}: 1.009,1.030, \mathrm{p}<0.01)$ measured at baseline and knee pain assessed after 10-13 year in the middle-aged adults (Table 1)

Conclusion: OA-related biochemical markers such as COMP and MMP-3 were positively associated with knee pain in population-based middle-aged adults. These results suggest biochemical markers measured in middle-aged adults may be used as a marker of joint pain

Acknowledgements: AS is supported by International Graduate Research Scholarship, University of Tasmania.

Disclosure of Interests: Ambrish Singh Employee of: Has worked in the past for Abbott and Eli Lilly and Company, Leigh Blizzard: None declared, Alison Venn: None declared, Graeme Jones: None declared, John Burgess: None declared Venkat Parameswaran: None declared, Changhai Ding: None declared, Benny Antony: None declared

DOI: 10.1136/annrheumdis-2021-eular.98

\section{POS0191 \\ THE VALUE OF MIR-20B, MIR-22, MIR-26A, MIR-125B AND MIR-221 IN RHEUMATOID ARTHRITIS}

M. Ciesla ${ }^{1}$, B. Kolarz ${ }^{1}$, M. Majdan ${ }^{2}$, M. Dryglewska ${ }^{2} .{ }^{1}$ University of Rzeszow, College of Medical Sciences, Rzeszow, Poland; ${ }^{2}$ Medical University of Lublin, Department of Rheumatology and Connective Tissue Diseases, Lublin, Poland

Background: Micro-RNAs (miRNAs) are an endogenous small, single-stranded, non-coding RNAs with a 18-25 nucleotide long and have been reported as a potential extracellular biomarkers of various diseases. They mainly decrease the gene expression by inhibiting the translation or cause mRNA destabilization. Objectives: The aim of the study was to identify miRNAs whose plasma expression level is associated with RA prevalence and/or activity.

Methods: A total of 74 unrelated individuals, 50 with RA and 24 in a control group were enrolled to the study. Real-time PCR was used to evaluate the plasma expression levels of 5 miRNAs: miR-20b, miR-22 miR-26a, miR-125b, miR-221. Results: We found the differences in four out of five evaluated miRs between RA and $\mathrm{HC}$ group - miR-26a, $\mathrm{p}^{<} 0.0001$; miR-125b, $\mathrm{p}<0.0001$; miR-20b $\mathrm{p}<0.0001$; miR $22, p=0.005$. Graphical presentation of the results is shown in Figure 1. The logistic regression results showed that miR-22 $(p=0.0003)$ and miR-26a $(p=0.049)$ are the most important molecules distinguishing RA patients and healthy controls in the study. MiR-22 was positively correlated with ESR $\left(r_{s}=0.41\right)$, CRP $(r=0.49)$ and DAS28 $(r=0.33)$ and miR-26a was positively correlated with ESR $\left(r_{s}^{s}=0.49\right)$, CRP $\left(r_{s}=0.41\right)$, number of swelling joints $\left(r_{s}=0.43\right)$, number of painful joints $(r=0.74)$ and DAS28 $(r=0.63)$. Moreover, miR-22 expression was different between rheumatoid factor (RF) positive and RF negative patients $(p=0.04)$

Conclusion: The results showed that miR-22 ( $p=0.0003)$ and miR-26a $(p=0.049)$ may be the most useful in evaluated panel of miRs distinguishing RA

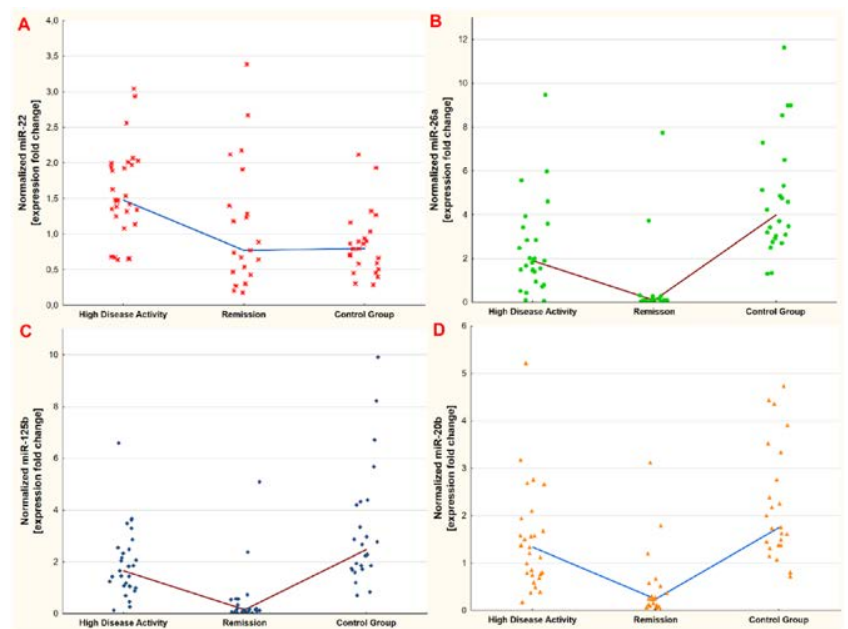


patients and HCs. In this study we demonstrated for the first time that plasma concentration of miR-22 may be considered as a potential molecular marker of RA exacerbation.

REFERENCES:

[1] Ouboussad, L., Hunt, L., Hensor, E.M.A. et al. Profiling microRNAs in individuals at risk of progression to rheumatoid arthritis. Arthritis Res Ther 2017 19, 288.

[2] Churov AV, Oleinik EK, Knip M. MicroRNAs in rheumatoid arthritis: altered expression and diagnostic potential. Autoimmun Rev. 2015 14(11):1029-37.Figure 1. Diagrams from $A$ to $D$ show the expression levels of miR-22, miR-26a, miR-125b and miR-20b, respectively. The median values of expression have been connected by a line.

Table 1. Spearman's rank correlation between micro-RNA-22 and microRNA-26 and the clinical variables.

\begin{tabular}{llllllllll}
\hline miRs $\backslash$ clinical variable Age & \multicolumn{1}{c}{ Disease duration ESR CRP SJC TJC } & DAS-28 & ACPA RF \\
\hline miR-22 & 0.09 & -0.27 & $\mathbf{0 . 4 1}$ & $\mathbf{0 . 4 9}$ & 0.26 & 0.21 & $\mathbf{0 . 3 3}$ & 0.24 & 0.16 \\
miR-26a & 0.2 & 0.14 & $\mathbf{0 . 4 9}$ & $\mathbf{0 . 4 1}$ & $\mathbf{0 . 4 3}$ & $\mathbf{0 . 7 4}$ & $\mathbf{0 . 6 3}$ & 0.26 & 0.16
\end{tabular}

The significant correlations were bolded and indicated by red. Abbreviations: ACPA, anti-citrullinated protein antibodies; CRP, C-reactive protein; SJC, swollen joint count; TJC, tender joint count; DAS-28, disease activity score 28 ; ESR, erythrocyte sedimentation rate; RF, rheumatoid factor.

Disclosure of Interests: None declared

DOI: 10.1136/annrheumdis-2021-eular.443

\section{PsA treatment: what is new?}

\section{POS0192 PROGNOSTIC FACTORS ASSOCIATED WITH ACHIEVING MINIMAL DISEASE ACTIVITY IN EARLY PSORIATIC ARTHRITIS PATIENTS}

E. Loginova ${ }^{1}$, T. Korotaeva ${ }^{1}$, E. Gubar ${ }^{1}$, S. Glukhova ${ }^{2}{ }^{1}$ V. A. Nasonova Research Institute of Rheumatology, Spondyloarthritis and psoriatic arthritis, Moscow, Russian Federation; ${ }^{2}$ V. A. Nasonova Research Institute of Rheumatology, Medical and Social Problems in Rheumatology, Moscow, Russian Federation

Background: The goal of treat to target strategy (T2T) in psoriatic arthritis (PsA) is attaining remission or minimal disease activity (MDA). The benefits of T2T have been seen recently [1]. But prognostic factors for MDA achievement in PsA patients (pts) at an early-stage hasn't been studied yet.

Objectives: to determine the prognostic factors associated with MDA achievement within 12 months (mos.) of treatment according to T2T strategy in early PsA pts.

Methods: 77 pts (M/F=36/41) with early active PsA fulfilling the CASPAR criteria were included. Mean age $36.9 \pm 10.45$ years (yrs.), PsA duration $11.1 \pm 10.0$ mos. Psoriasis (PsO) duration 82.8 \pm 92.1 mos. At baseline (BL) and at 12 mos. of therapy PsA activity by tender joint count (TJC)/68, swelling joint count (SJC)/66, Pain (VAS), Patient global assessment disease activity (PtGA, VAS), CRP mg/l, dactylitis, enthesitis by LEI and plantar fascia, BSA (\%), HAQ and fatigue by FACIT (Functional Assessment of Chronic Illness Therapy) Fatigue Scale (Version 4) were evaluated. A score FACIT $<30$ indicates severe fatigue and $>30$ - less fatigue. All pts was given therapy with Methotrexate (MTX) s/c. After 3-9 mos. of ineffectiveness of MTX treatment 29 pts were given biologic DMARDs. By 12 mos. of therapy, the proportion of pts who had reached MDA (5/7) were calculated. Pts were split into 2 groups: MDA + $(n=45)$ and MDA - $(n=32)$. The one-factor model of logistic regression was used to identify a group of features that are associated with MDA achievement. M \pm SD, Me [Q25; Q75], Min-Max, \%, t-test, Pierson- $\chi 2$, Manna-Whitney tests, ORs with $95 \% \mathrm{Cl}$ were performed. All $\mathrm{p}<0.05$, were considered to indicate statistical significance.

Results: Comparative analysis in both groups and one-factor model of logistic regression showed the following features at $B L$ were associated with MDA achievement: TJC/SJC $<3(p<0.001), P G A \leq 20 \mathrm{~mm}(p<0.001)$, Pain (VAS) $\leq$ $15 \mathrm{~mm}(\mathrm{p}<0.001), \mathrm{CRP} \leq 5 \mathrm{mg} / \mathrm{l}(\mathrm{p}<0.03), \mathrm{HAQ} \leq 0.5(\mathrm{p}<0.001)$, FACIT $>30(p<$ $0.021)$, absent of entesitis $(p<0.003)$, dactylitis $(p<0.029)$ and nail damage $(p<$ 0.012). Early PsA pts with combination of these features at first visit have more chance to achieve MDA within 12 mos in comparison to PsA pts without them, $\mathrm{OR}=9.684$ [Cl 95\% 4.6-20.4]. (Figure 1).

Conclusion: It is a combination of features at first visit to clinic - TJC, SJC < $3, \mathrm{PGA} \leq 20 \mathrm{~mm}$, pain $\leq 15 \mathrm{~mm}, \mathrm{CRP} \leq 5 \mathrm{mg} / \mathrm{l}, \mathrm{HAQ} \leq 0.5$, FACIT $>30$ points, absent of entesitis, dactylitis and nail PsO - that constitutes a clinical prognostic factors for MDA achievement within 12 mos of T2T strategy in early PsA pts. REFERENCES:

[1] Coates LC, et al. Lancet. 2015 Dec 19;386(10012):2489-98. doi: 10.1016/ S0140-6736(15)00347-5

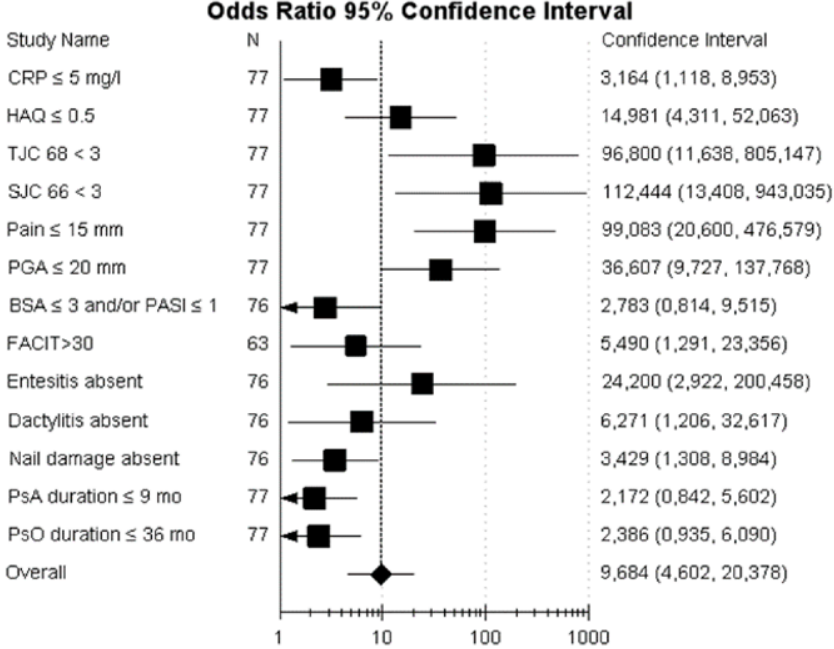

Figure 1. The prognostic factors associated with achievement MDA within 12 months in early PsA pts

Disclosure of Interests: None declared DOI: 10.1136/annrheumdis-2021-eular.1704

\begin{tabular}{|l|l|}
\hline POS0193 & DAS28-CRP GUIDED TREAT-TO-TARGET TAPERING \\
& OF TUMOR NECROSIS FACTOR INHIBITORS IN \\
& PSORIATIC ARTHRITIS: A RETROSPECTIVE COHORT \\
& STUDY.
\end{tabular}

C. Michielsens $^{1,2}$, N. Den Broeder ${ }^{1,2}$, M. Mulder $^{1,2}$, M. Wenink ${ }^{1}$, F. Van den Hoogen ${ }^{1,2}$, L. M. Verhoef ${ }^{1}$, A. Den Broeder ${ }^{1,2} .{ }^{1}$ Sint Maartenskliniek, Rheumatology, Nijmegen, Netherlands: ${ }^{2}$ Radboud university medical center, Radboud Institute for Health Sciences, Nijmegen, Netherlands

Background: Tumor Necrosis Factor inhibitors (TNFi) have proven to be safe and effective in the treatment of psoriatic arthritis (PsA) [1]. However, they carry disadvantages, such as adverse effects, patient burden, and costs, which could be reduced by treat-to-target (T2T) tapering. Although there is lack of high level evidence, guidelines suggest that T2T tapering and discontinuation might be considered, but no studies comparing this strategy to continuation in PsA were published [2]

Objectives: To assess the effect of T2T TNFi tapering on disease activity and TNFi dosage in PsA patients with low disease activity (LDA).

Methods: PsA patients using TNFi who visited the clinic between April 2012 and October 2018 were included if eligible for tapering, according to local protocol: $\geq$ 6 months of TNFi treatment and $\geq 6$ months of at least LDA (DAS28-CRP $<2.4$ (or 2.9 in patients with disease duration $>3$ years) or by judgement of physician and patient). Patients with concomitant inflammatory disease preventing tapering were excluded. Three different time periods were defined: i) full-dose TNFi continuation; ii) TNFi tapering; iii) stable TNFi dosage after tapering. A mixedmodel analysis was used to estimate mean DAS28-CRP during these three time periods. This model included: age, gender, disease duration, and the following time-varying components: current dose reduction status (three time periods mentioned above), time since eligibility for tapering and use of concomitant conventional synthetic Disease-Modifying Antirheumatic Drugs (csDMARDs), and a random intercept to account for inter-patient variability. Furthermore, a mean percentage of the Daily Defined Dose (\%DDD) was calculated as secondary outcome.

Results: 152 patients were included, with a mean of 6.5 DAS28-CRP measurements, of whom 125 attempted dose reduction during follow-up. Median follow-up duration was 41 months (Inter Quartile Range (IQR) 24-59) for patients who never attempted dose reduction and 43 months (IQR 28-58) for those who did (table 1). The mixed model showed no significant difference in DAS28-CRP between the three time periods. Adjusted for gender, age, disease duration at baseline, time since follow-up and csDMARD use, the mean DAS28-CRP was 1.91 in the continuation period (95\% Confidence Interval (CI) [1.76-2.05]) and 2.0 in both the TNFi tapering $(95 \% \mathrm{Cl}$ [1.90-2.12], difference with continuation: 0.11 $\mathrm{p}=0.19)$ and stable TNFi dosage after tapering $(95 \% \mathrm{Cl} 1.88-2.11]$, difference with continuation: $0.09, p=0.31$ ) period. The mean percentage of the DDD for the three time periods was $107 \%$ for the continuation period; $62 \%$ in the TNFi tapering period and $79 \%$ in the stable TNFi dosage period.

Conclusion: T2T tapering of TNFi appears to have no negative effects on disease activity in PsA patients compared with full dose continuation, and reduces 